\title{
The application of a Bayesian approach to assess the seismic vulnerability of historical centers.
}

\author{
S. Taffarel, G. P. Campostrini, L. Rosato, C. Marson, F. da Porto \& C. Modena \\ University of Padova, Department of Civil, Environmental and Architectural Engineering, 35131 Padova, \\ Italy
}

\begin{abstract}
The seismic vulnerability of historical centers at a territorial scale cannot be assessed performing detailed analysis which are usually adopted at the single building scale. In fact, a traditional complete survey would be extremely time-consuming and not sustainable for this purpose.

The approach described in this paper is based on the idea that it is possible to infer quantities which cannot be directly detected from buildings outside inspection starting from parameters that can be measured. In order to achieve this purpose, a Bayesian approach is applied, updating initial hypotheses when new data become available. In this context, the procedure herein proposed aims at applying a probabilistic approach instead of a deterministic one to define facades inter-storey height starting from buildings height knowledge. In order to validate the method, for out of plane local mechanisms of collapse (walls overturning), horizontal loads multiplier $\alpha_{0}$ values are calculated and compared to results obtained by using data collected on-site.
\end{abstract}

\section{INTRODUCTION}

Seismic vulnerability assessment on a territorial scale, implicitly related to the broader issue of seismic risk mitigation and reduction, is conditioned by factors of uncertainty related to the data process, that inevitably impact the analysis. These variabilities are related to the nature of the approach (rapid approach), which is anyway the more functional and adaptable procedure considering both the scale at which the analysis is conducted (territorial scale) and the need of time and costs limitation during survey and data processing phase.

The uncertainty of information collected during the on-site activities, due to the execution of buildings surveys mainly by adopting outside inspections and without on-site tests or investigations leads to a low level of knowledge (DPCM 2011). Nevertheless, it could be regarded as entirely consistent with the purposes of the carried out analysis. It is indeed important to underline that the main aim of a study on a large scale is the definition of preliminary vulnerability assessments for analyzed structures, obtaining a priority list of buildings that should be deeper analyzed (Calvi et al., 2006). The application of methodologies proving the vulnerability of buildings considering the survey uncertainty allows to significantly extend the analysis, including buildings characterized by lacking information about one or more data (geometric or typological ones) (Marson
2013, Taffarel 2015). As an example, the building total height and the size and position of walls openings can usually be measured with acceptable precision even from outside, by adopting traditional or remote sensing methods (aerial surveys). Procedures for vulnerability assessment adopting remote sensing are numerous and widely applied for both the post-earthquake damage assessment (Dong et al., 2013) and predictive seismic vulnerability assessment (Pittore at al., 2013). At the same time, the application of probabilistic approaches to face vulnerability assessment is increasing, involving the field of both seismic events and other natural risks (Tebaldi et al. 2004, Koutsourelakis 2010).

\section{CONSIDERATIONS ABOUT THE RELEVANCE OF THE THEME: NEW PROVISIONS ABOUT RISK MITIGATION MEASURES}

Mitigation and reduction of seismic risk at a territorial scale is a topical theme: a demonstration of this increasing awareness is underlined by the involvement of scientific and technological specialists in this topic (ISO 13822 2001, ISO/DIS 138242008 , DPCM 12/10/2007, DM 14/01/2008, Circular n. 617 2009). Gradually, the growing interest is turning into a continuous updating of scientific and technical standards (methodologies and design practices) re- 
lated to the safety of buildings subjected to seismic actions (MIBAC 2010). The Italian Ministry of Cultural Heritage reached the awareness that its involvement in practices of good maintenance is essential to ensure buildings structural safety. In this context, initiatives to increase the efficiency of activities involving the safeguard of historic architectural heritage are implemented with the aim of encouraging the establishment of measures for the seismic risk mitigation of historic centres in its own central and local offices.

Among the most significant initiatives, the Circular n. 15 "Provisions on the protection of architectural heritage and seismic risk mitigation" (Circular n.15, 2015) provides a new incremental approach that involves both the implementation of local interventions on buildings improving structural safety without involving sensitive additional costs and the improvement of reliability of seismic risk maps.

Prevention is one of the main topics of the abovementioned circular, given the need to increase buildings seismic safety, which can be applied only if a preliminary widespread and deep knowledge of buildings vulnerabilities and possible intervention applicable on architectural heritage can be obtained. Buildings knowledge can only be achieved through the systematic collection of information about them; data can be gathered by adopting a specific form attached to the circular to be completed by technicians and practitioners when presenting practices to perform extraordinary maintenance or seismic improvement intervention on buildings (or part of them) listed as "cultural heritage".

A virtuous process is ongoing, considering that the real improvement of seismic security of historic centers is only achievable by activating processes that continuously involves all the people implicated in the construction process (owners, designers, builders, government offices, etc.).

\section{DESCRIPTION OF THE BAYESIAN APPROACH}

In view of previous considerations, it is clear that over the years there will be a continuous increase of available information about historical buildings located in the Italian territory. The need to understand how to use this large amount of data in the best way, by adopting procedures able to continuously update information and at the same time to fill the gaps related to the lack of information, is extremely important (Modena 2012). It is also fundamental to remember that data updating can take place without periodicity and that information could be obtained for single buildings time after time; moreover, they can not necessarily involve entire widespread areas but just single buildings or part of them. The proce- dure must guarantee the possibility of a continuous information updating.

The methodology herein proposed allows inferring quantities/data that cannot be directly detected on site starting from parameters that can be measured. In this context, a stochastic approach is applied instead of a deterministic one in order to provide probabilistic vulnerability assessments on a territorial scale through the application of a Bayesian approach (Modena, 2014). Considering the needs established above, the approach allows deducing buildings unknown information starting from collected certain data, updating initial probability density functions when new data becomes available.

The method can be synthesized by applying this simple scheme:

\section{prior distribution $\rightarrow$ data $\rightarrow$ posterior distribution}

This process, which provides a continuous learning experience acquisition when new data are obtained, is called Bayesian update.

If continuous random variables are used, Bayes theorem can be written as follows:

$$
{ }_{p}(\theta \mid y)=\frac{p(\theta) p(y \mid \theta)}{\int p(\theta) p(y \mid \theta) d \theta}
$$

where:

$-p(\theta)$ is the prior distribution (quantifies all information available before experimental results are observed)

$-p(\mathbf{y} \mid \boldsymbol{\theta})$ is the likelihood, which, as $\theta$ varies, represents the probability of obtaining observed experimental results

$-p(\boldsymbol{\theta} \mid \mathbf{y})$ is the posterior distribution and is the result of Bayesian inference, and represents final distribution after experimental results have been observed.

By collecting new data, the process can be iteratively repeated: the posterior distribution becomes the new prior distribution, and a new posterior probability density function can be obtained. This procedure can be repeated each time new data are available.

A prior distribution can be defined as a distribution conjugated to the adopted sample model (or equivalently to likelihood) if prior and posterior distributions are characterized by the same functional form (Liseo 2008). As an example, if a normal-inversegamma distribution is chosen as prior distribution and likelihood is a normal distribution, the resulting posterior distribution, obtained by applying Bayes theorem, is a normal-inverse-gamma. 
4 APPLICATION OF THE APPROACH TO THE LOCAL MECHANISMS OF COLLAPSE ANALYSIS

The proposed method is carried out by implementing the local mechanisms of collapse analyses.

In this context, it is essential to provide a general overview of the current Italian legislation in order to justify this application.

Circular. 617 (C8A.3), underlines that "the analysis of a structural unit, according to the methods applied for isolated buildings without adequate modeling or with an approximate modeling of the interaction with the adjacent buildings, assumes a conventional meaning. Therefore, it is assumed that the analysis of the global seismic capacity of the structural unit can be verified by the use of simplified methods [...] ". And yet (C8.7.1.1): "For the assessment of existing buildings, in addition to the global seismic analysis to be carried out by applying the methods prescribed by the new buildings standards [...] should be also considered the analysis of local mechanisms of collapse. When constructions do not show a clear global behavior, but react to an earthquake as a set of subsystems (local mechanisms), a global model has no correspondence with the real seismic behavior." Aggregate buildings, by their definition, are characterized by an articulated and not unitary genesis, which usually leads them to react to an earthquake as "a set of subsystems" (C 8.7.1.1).

Given these remarks, a study based on the analysis of the local mechanisms of collapse by the implementation of a probabilistic approach is undoubtedly significant. The out of plane local mechanisms of collapse involve walls orthogonally stricken by a seismic action. As an example, the definition of buildings vulnerability with respect to these types of mechanisms allows to identify facades facing the road that could be submitted to collapse if an earthquake occurs, preventing the transit of emergency vehicles. It is possible to establish, on the basis of such evaluations, suitable access and escape routes.

\section{THE CHOICE OF PARAMETERS}

First of all, the development of the described approach and its application to the local mechanisms of collapse analysis needs to define the parameters to be taken into account for the analyses.

Considering the innovativeness of this approach, in this first step the procedure is tested on simple cases. The method refinement is going to involve more parameters allowing the approach to be closer to real historical buildings configuration.

The study considers the analysis of freestanding walls. Their considered geometrical and mechanical parameters are:
- masonry properties;

- walls thickness;

- thickness variation between different floors;

- building height;

- inter-storey height;

- number of floors.

The procedure allows defining horizontal loads multiplier $\alpha_{0}$ of freestanding walls, on the basis of their thickness and inter-storey height variation.

Masonry properties are defined a priori, considering buildings vertical structures features. Geometrical input data treated as certain (easily identifiable) ones are building total height and number of floors. These data are easily available since they can be obtained through buildings outside inspections, limiting time and costs consuming. Such information may be reached even eliminating the on-site survey phase: data can be easily recovered through the use of online maps and aero photogrammetry (Fabris 2013). Buildings observation by using online maps allows the identification of the number of floors of each building (Figure 1). The photogrammetry can be used as a useful tool for the definition of buildings total heights. It can be obtained calculating the difference between the roofs height and the height of some measured points on the ground level, located in proximity of a considered building. It is necessary to measure multiple points on the ground floor because buildings are not on a perfectly flat soil. Measurements should be repeated using multiple stereo pairs averaging obtained results.

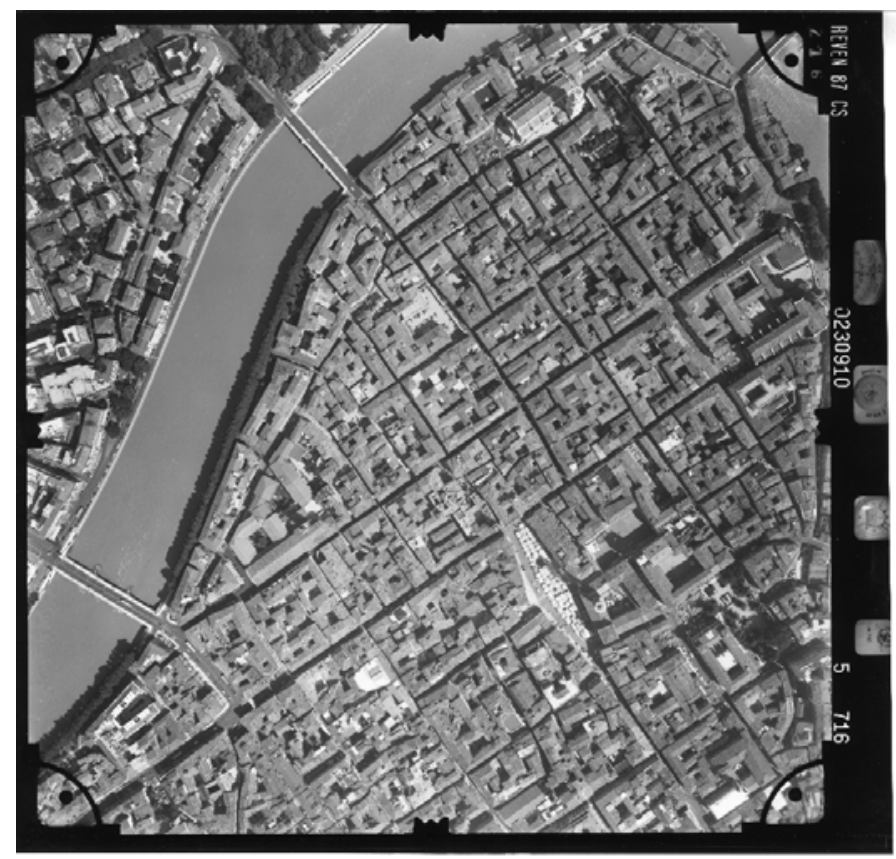

Figure 1. Example of aero photogrammetry applied to Verona (Italy) historic center: the availability of a huge number of pictures taken on parallel strips allows obtaining several points of view of each building by limiting shadows and undercuts and obtaining information about openings on buildings facades. 


\section{COMPOSITIONAL DATA}

\subsection{Statistical analysis}

Implementation of vulnerability analyses requires the knowledge of a series of physical quantities which describe the behavior of buildings. Some of these quantities are, by their nature, not precisely controllable (material characteristics, seismic input, etc.) and uncertainties related to their quantification can be reduced but not eliminated. Other quantities can be measured with sufficient precision to consider them as fixed. Geometrical aspects (building height, inter-storey height, walls thickness, position and thickness of inner walls, etc.), even if they can be theoretically measured with a certain level of precision, can be treated as random variables, assigning them not a fixed value but a suitable probability density function (PDF - Probability Density Function).

Quantities that can be considered by adopting this approach are:

- walls thickness;

- thickness variation between different floors;

- inter-storey height.

In this paper the definition of inter-storey height starting from the knowledge of buildings height is described.

From a theoretical point of view, the problem could be solved by adopting a compositional data approach (Aitchison 1982a, 1982b).

\subsection{Theoretical aspects: the nature of compositional data}

There are situations in which data, even if they can assume different values, are bound to have a certain value as sum of their quantities. This situation is quite frequent: for example, data which represent the composition (compositional data) of soils, rocks or other substances can be described as a percentage whose sum is 100 . The same situation can be observed in the case of buildings, where interstorey heights can assume different values, but their sum must be equal to building height. In this case, the components usually have values that are comparable with one another, being in some cases practically constant. It is possible to consider as an example modern multistorey buildings, in which the abovementioned situation often occurs and is compliant with requirements of construction speed, energy efficiency, optimization of space etc. A certain regularity is also detectable in historical masonry buildings. In fact, in the case of two-storey buildings, it is not common for the floors having different heights. In some cases, the use of statistical approaches, that do not recognize the compositional nature of data, can lead to erroneous conclusions or at least approximated ones.
From a theoretical point of view, the problem could be described considering the generic composition as an n-dimensional vector.

$h=\left\lfloor\begin{array}{llll}h_{1} & h_{2} & \ldots & h_{n}\end{array}\right\rfloor$

where $h_{1} \quad h_{2} \quad \ldots \quad h_{n}$ represent the inter-storey heights of a building. This vector can be standardized in order to obtain that the sum of the components is equal to 1 .

$$
x=\left[\begin{array}{llll}
x_{1} & x_{2} & \ldots & x_{n}
\end{array}\right]=\left[\begin{array}{llll}
\frac{h_{1}}{\sum_{1}^{n} h_{i}} & \frac{h_{2}}{\sum_{1}^{n} h_{i}} & \ldots & \frac{h_{n}}{\sum_{1}^{n} h_{i}}
\end{array}\right]
$$

where:

- $\sum_{1}^{n} h_{i}$ is the building height;

- $\mathrm{n}$ is the dimension of $\mathrm{x}$ vector;

- $\mathrm{x}_{\mathrm{i}}$ values are positive and smaller than 1 .

By adopting a further transformation:

$$
\begin{aligned}
& y=\left[\begin{array}{llll}
y_{1} & y_{2} & \ldots & y_{n-1}
\end{array}\right]= \\
& =\left[\begin{array}{lll}
\log \left(\frac{x_{1}}{x_{n}}\right) & \log \left(\frac{x_{2}}{x_{n}}\right) \quad \ldots & \left.\log \left(\frac{x_{n-1}}{x_{n}}\right)\right]
\end{array}\right.
\end{aligned}
$$

which is a vector whose components assume their values in the set of real numbers.

The generation of $y$ values is made by assuming that they follow normal multivariate distributions characterized by ( $n-1)$ dimension, where $n$ is the number of floors. Parameters that describe these distributions are easily quantifiable by means of specific software as soon as an adequate number of information is available.

Not being subjected to constraints, this statistical analysis can also be used for buildings with a number of floors greater than 2. Obviously in this case a multivariate analysis must be carried out. Looking at (4) it is possible to notice that the size of vector $y$ is $\mathrm{n}-1$; if analyzed buildings have more than 2 floors $(n>2)$, a y vector whose dimension is bigger than 1 is the result of analysis. In this case, the application of a multivariate analysis is necessary.

Following the steps in reverse, $h_{i}$ values can be derived from $y_{i}$ values.

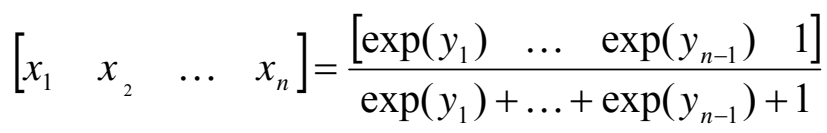

And then:

$$
\left[\begin{array}{llll}
h_{1} & h_{2} & \ldots & h_{n}
\end{array}\right]=\left[\begin{array}{llll}
x_{1} & x_{2} & \ldots & x_{n}
\end{array}\right] \cdot \sum_{1}^{n} h_{i}
$$




\subsection{An application of the compositional data approach}

A simple application of the method to buildings facades, for which the height of both building and storeys is known, is herein proposed in order to demonstrate the effectiveness of the approach.

The computational code is implemented by adopting the software R (R DCT 2008).

The code allows estimating the storey heights of a building starting from the knowledge of its total height. The implementation of a Bayesian approach is considered (Jackman 2009).

The case study considers a two-storey building in the historic center of the city of Timisoara (Banat region, Romania). The choice is linked to the availability of a large amount of data for the historic center of the city, where expeditious surveys were executed (Figure 2).

The data availability of 36 buildings having characteristics which are similar to those of the studied buildings (number of floors, type of vertical structures, etc.) allows to implement the Bayesian update.

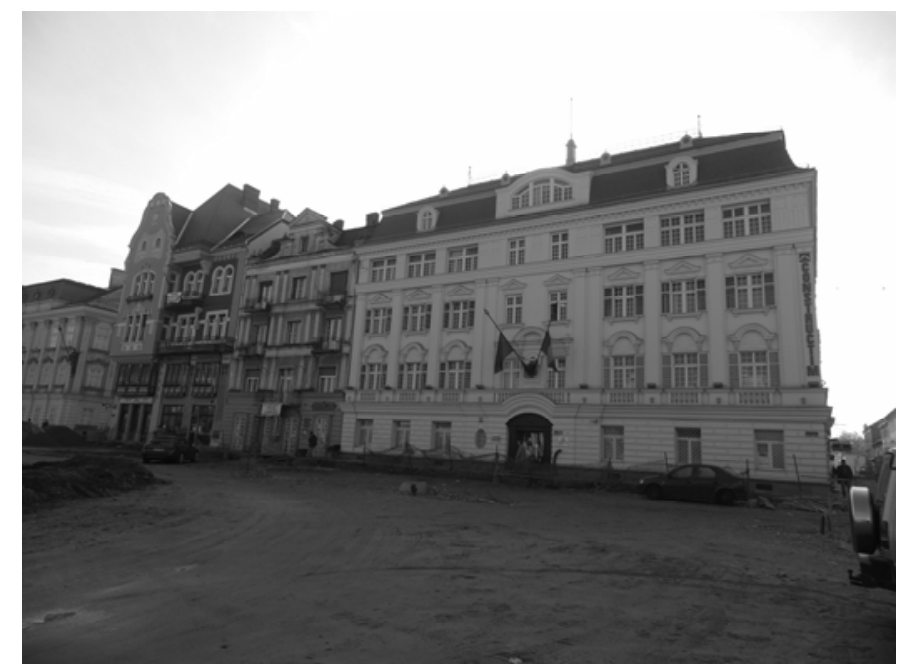

Figure 2. Buildings belonging to Timisoara historical city centre.

The first step of the procedure requires the definition of a prior distribution, which is obtained considering the use of data related to a limited number of buildings. The prior can be described as a normalinverse-gamma distribution, which can be defined as the product of an inverse gamma and a normal distribution. Effectively, the conditional distribution of population mean $\mu$ given the data and $\sigma^{2}$ is normal, and $\sigma^{2}$ given the data is inverse-gamma (Hoff 2009). The prior is defined by inserting a limited number of samples related to the log ratio described in (4). Obviously, updating the distribution by inserting a further substantial amount of data related to other twostorey surveyed buildings, a posterior distribution is obtained and the shape of the obtained normal- inverse-gamma distribution is adjusted considering the new entered data. (Figure 3 ).

At this stage, it is possible to generate samples starting from the conjugate posterior distribution by applying the Monte Carlo method (Gamerman 2006).

Each obtained $\left(\mu, \sigma^{2}\right)$ couple defines a normal distribution from which the software extrapolates a value of the log ratio; the procedure is applied as many times as the number of required samples.

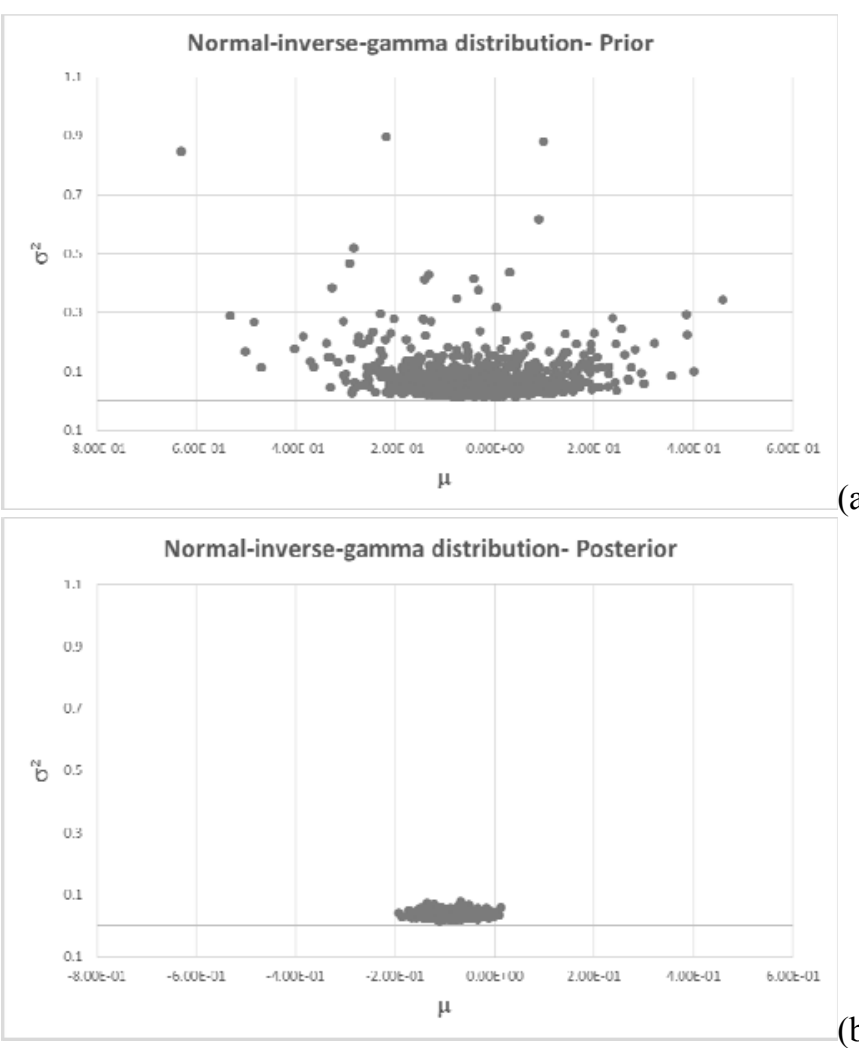

Figure 3. Prior (a) and posterior (b) normal-inverse-gamma distribution. Scatterplots representing prior and posterior normal-inverse-gamma are obtained generating 1000 samples both from the prior and the posterior by adopting the Monte Carlo method

By way of example, it has been requested to the software to generate 20 samples.

By applying the formula described above, obtained $\log$ ratio are then used in order to define possible $h_{i}$ values.

The method is applied to a two-storey building in order to simplify the procedure by using a univariate distribution.

The analyzed two-storey building is characterized by:

-building height: $8,9 \mathrm{~m}$

-ground floor inter-storey height: $4 \mathrm{~m}$

-first floor inter-storey height: $4,9 \mathrm{~m}$.

Building total height is inserted in the code as a known parameter; the aim of the analysis is to obtain inter-storey heights starting from the knowledge of building height.

By comparing the values obtained from the implementation of $\mathrm{R}$ code and the real inter-storey ones, it 
is possible to observe that obtained results do not significantly differ from values surveyed on-site. The mean value of samples is compared to the real one. Following, geometrical data obtained by adopting $\mathrm{R}$ code are reported:

-ground floor inter-storey height: $4,33 \mathrm{~m}$

-first floor inter-storey height: $4,57 \mathrm{~m}$.

A difference of $33 \mathrm{~cm}$ is detectable between the measured values and those obtained by the calculation. Considering results in view of the calculation of $\alpha_{0}$ (and, as a consequence, in view of the implementation of local mechanisms of collapse linear analyses), differences between each inter-storey height are not significant.

The example is carried out considering fixed values of walls thickness (in this case, $0,6 \mathrm{~m}$ for the ground floor and $0,45 \mathrm{~m}$ for the first floor).

Following, the $\alpha_{0}$ values obtained in the two cases are reported:

-real case $\alpha_{0}$ value: $\alpha_{0}=0,049$

-mean $\alpha_{0}$ value by using R code: $\alpha_{0}=0,055$

The same procedure is then applied to the other 35 abovementioned buildings (surveyed on-site) in order to compare the results in terms of height.

The difference between the obtained average values and the real ones reaches a maximum of $59 \mathrm{~cm}$; these values are widely acceptable considering the purpose of the analysis. As in the previous case, $\alpha_{0}$ values are calculated, showing a difference of 0,008 $\left(\alpha_{0}=0,072\right.$ - real case $-, \alpha_{0}=0,08$ - by using $R$ code $)$.

\section{CONCLUSIONS}

The method proposed in this paper describes one of the steps of a new probabilistic approach implemented by the University of Padova in order to assess buildings seismic vulnerability at an urban scale.

The application of the theory of compositional data allows defining probabilistically floors heights starting from the knowledge of buildings height.

This probabilistic approach allows calculating and verifying local mechanisms of collapse analyses, considering that obtained results are more precise if incoming information are updated.

Currently the procedure is conducted taking into account a certain number of simplifications (for example, the analyzed walls are freestanding walls), but it can be gradually refined by including in the analysis other geometric or typological information.

The process is at a preliminary phase, but the procedure seems promising and adapts to the purposes of a territorial scale analysis, allowing considering uncertainties related to the collection of data or data missing.

\section{REFERENCES}

Aitchison, J. (1982a). A Concise Guide to Compositional Data Analysis. Available on-line:

http://www.leg.ufpr.br/doku.php

Aitchison J. (1982b). The Statistical Analysis of Compositional Data in Journal of the Royal Statistical Society. Series B (Methodological), Vol. 44, No. 2. (1982), pp. 139-177.

Calvi, G.M., Pinho, R., Magenes, G., Bommer, J.J., RestrepoVelez, L.F., Vrowley, H. Development of seismic vulnerability assessment methodologies over the past 30 years, in ISET Journal of Earthquake Technology, 2006, Paper 472, Vol. 43 (3), 75-104.

CEN TC 346 Conservation of cultural property - WG1: Condition survey of immovable heritage; WG2N 018: Diagnosis of building structures

Gamerman, D., Lopes, H. F.(2006). Markov Chain Monte Carlo. Chapman \& Hall/CRC.

Direttiva del presidente del consiglio dei ministri DPCM 12/10/2007 (updated by DPCM 09/02/2011). Guidelines for evaluation and mitigation of seismic risk to cultural heritage with reference to technical standard for constructions.

Dong, L., Shan, J. A comprehensive review of earthquakeinduced building damage detection with remote sensing techniques, in ISPRS Journal of Photogrammetry and Remote Sensing, 2013, Vol. 84, 85-99

Fabris, M., Achilli, V., Campostrini, G. P., Modena, C. (2013), L'aerofotogrammetria digitale per la stima delle caratteristiche strutturali degli edifici. In A.N.I.D.I.S 2013, XV convegno - L'ingegneria Sismica in Italia, Padova, Italy, 30 June -4 July 2013

Hoff, P. D. (2009) A First Course in Bayesian Statistical Methods. Springer ed.

ISO 13822 (2001) Bases for design of structures-Assessment of existing structures - ANNEX I (Informative) Historic structures

ISO/DIS 13824 (2008) General principles on risk assessment of systems involving structures

Jackman, S. (2009). Bayesian Analysis for the Social Sciences Wiley ed.

Koutsourelakis, P.S. (2010), Assessing structural vulnerability against earthquakes using multi-dimensional fragility surfaces: A Bayesian framework. In Probabilistic Engineering Mechanics n. 25, 49-60

Liseo, B. (2008) Introduzione alla statistica bayesiana, Springer ed. [In Italian]

Marson, C., Taffarel, S., Bettiol, G., Munari, M., Modena, C. , Cialone, G., Cifani, G., Mannella, A. and Petracca, A. (2013) Sviluppo dei Piani di Ricostruzione di borghi dell'aquilano colpiti dal sisma del 6 aprile 2009, in A.N.I.D.I.S 2013, L'ingegneria Sismica in Italia, Padova, Italia, Conference Proceedings [In Italian]

Ministero dei beni e delle Attività Culturali e del Turismo (2015). Circular n.15 (30/04/15). Provisions on the protection of architectural heritage and seismic risk mitigation [In Italian]

Ministero dei beni e delle Attività Culturali MIBAC (2010). Linee Guida per la valutazione e riduzione del rischio sismico del patrimonio culturale allineate alle nuove Norme tecniche per le costruzioni (D.M 14 gennaio 2008), Circolare 26 Segretario Generale MiBAC, Prot. 10953 [In Italian]

Ministero delle Infrastrutture e dei Trasporti (2009) Circolare esplicativa 02/02/2009 n. 617. Istruzioni per l'applicazione delle «Nuove norme tecniche per le costruzioni». D.M. 14/02/2008 [In Italian]

Ministero delle Infrastrutture e dei Trasporti (2008) NTC2008 - Norme tecniche per le costruzioni. D.M. 14/01/2008 [In Italian] 
Modena, C. (2014). Una proposta operativa di approccio sostenibile alla valutazione e mitigazione del rischio sismico dei centri storici. In I quaderni della Soprintendenza per $i$ Beni architettonici paesaggistici per le provincie di Verona Rovigo Vicenza, vol. VI, 2014 [In Italian]

Pittore, M., Wieland, M.. Toward a rapid probabilistic seismic vulnerability assessment using satellite and ground-based remote sensing in Natural Hazards, 2013, Vol. 68 Issue 1, $115-145$

R Development Core Team DCT (2008). R: A language and environment for statistical computing. R Foundation for Statistical Computing, Vienna, Austria. ISBN 3-90005107-0, URL http://www.R-project.org.

Taffarel, S., Marson, C., Bettiol, G., Munari, M., da Porto, F., Valluzzi, M.R., and Modena, C., 2015, The structural issue of the reconstruction plan of Castelvecchio Calvisio historical centre. In Conservation - Reconstruction. Small historic centres conservation in the midst of change, EAAE Transactions on Architectural Education n. 64, EAAE, Hasselt (Belgium), 2015, ISBN no: 978-2-930301-63-1.

Tebaldi, C., Snith, R.L., Nychka, D., Mearns, L.O., 2004, Quantifying uncertainty in projections of regional climate change: a Bayesian approach to the analysis of multimodel ensembles. In Jornal of Climate n. 18, 1524-1540 